Published in final edited form as:

Pediatr Pulmonol. 2018 May ; 53(5): 592-598. doi:10.1002/ppul.23975.

\title{
Difficult Conversations: Discussing Prognosis with Children with Cystic Fibrosis
}

\author{
Julia Gray Farber, MD ${ }^{1}$, Mary G. Prieur, $\mathrm{PhD}^{2}$, Christine Roach, RN, BSN ${ }^{3}$, Rosemary Shay, \\ BA $^{1}$, Michelle Walter, $\mathbf{D O}^{4}$, Drucy Borowitz, $\mathbf{M D}^{3,5}$, and Elisabeth P. Dellon, $\mathbf{M D}, \mathbf{M P H}^{6}$ \\ ${ }^{1}$ University of North Carolina School of Medicine, Chapel Hill, NC, USA \\ ${ }^{2}$ Departments of Psychiatry \& Pediatrics, University of North Carolina School of Medicine, Chapel \\ Hill, NC, USA \\ ${ }^{3}$ Department of Pediatrics, Jacobs School of Medicine, University at Buffalo of State University of \\ New York, Buffalo, NY, USA \\ ${ }^{4}$ Department of Geriatrics and Palliative Medicine, Jacobs School of Medicine, University at \\ Buffalo of State University of New York, Buffalo, NY, USA \\ ${ }^{5}$ Cystic Fibrosis Foundation, Bethesda, MD, USA \\ ${ }^{6}$ Department of Pediatrics, Division of Pulmonology, University of North Carolina School of \\ Medicine, Chapel Hill, NC, USA
}

\section{Summary}

Background-Despite the chronic, progressive, and life-threatening nature of cystic fibrosis (CF), there are no guidelines for when and how to communicate prognosis to children with $\mathrm{CF}$.

\begin{abstract}
Methods-Semi-structured interviews with young adults with CF, parents of young adults with $\mathrm{CF}$, and multidisciplinary $\mathrm{CF}$ health care providers assessed recall of and practices for communicating about prognosis. Recommendations for improvements were also solicited.
\end{abstract}

Results-Young adults with CF recalled learning that life expectancy is limited by CF between the ages of 8 and 16 years, and that $\mathrm{CF}$ is a progressive disease between the ages of 7 and 19 years. They reported that the information often came from CF physicians or from online resources. Patients and parents reported earlier knowledge of prognosis than providers assumed. While learning about prognosis caused sadness and stress for some patients and families, others denied negative feelings. Interestingly, most patients reported that disclosure of prognosis had minimal impact on their adherence and treatment goals. Patients and parents reported wanting physicians to be involved in conversations about prognosis. However, providers noted several barriers to discussing prognosis, including their own reluctance, time limitations, and uncertainty about appropriate timing and content of communication.

Conclusions-Communication about prognosis is important but also difficult for providers, patients, and families. Appropriately timed conversations, using tools to facilitate communication, could ensure patients receive timely, accurate information.

\section{Keywords}

Cystic fibrosis; prognosis; communication 


\section{Introduction}

In the 1950s, very few individuals with cystic fibrosis (CF) survived to adolescence. Today, the predicted median survival is 47 years $^{1}$. Despite attention to greater longevity, there are no guidelines or recommended timelines for sharing information about prognosis with patients with CF. Adults with CF report dissatisfaction with health care provider communication and general resources for coping with the stressors of living with chronic disease. In a survey of adults with CF, one-third reported lack of information on "ways to deal with the unpredictability of the future." 2 The authors recommended that providers be proactive, rather than reactive, with earlier initiation of conversations about self-management and future planning. This can be challenging for CF providers; other studies in CF suggest both patient/parent and provider barriers to communication about serious or sensitive topics like advance care planning and sexual health, including knowing when to initiate conversations and lack of provider comfort and training in sensitive communication ${ }^{3-7}$

The pediatric palliative care community has emphasized the importance of open and direct communication with children at an appropriate developmental level ${ }^{8-12}$. Clear, supportive, intentional communication with children and their parents is essential to providing quality care in pediatrics, in every setting from primary care to intensive care to chronic illness management ${ }^{13}$. Children and their families want to be active participants in their health care and decision- making. Knowledge about one's condition may offer a sense of control ${ }^{14}$. The perception of clear and honest communication also affects one's perception of his or her health care.

There is little information in the literature about how children with CF learn about prognosis. In one older study, children with $\mathrm{CF}$ and their parents were surveyed about the natural history of $\mathrm{CF}^{15}$. Patients expressed a desire for more information about their futures and about coping with chronic disease. Adolescents indicated preferring to receive this information from their providers rather than their parents. However, most recalled few opportunities to discuss the daily challenges of living with $\mathrm{CF}$ with their providers. Since this study, there have been significant improvements in the treatment of CF, leading to longer life expectancy; however, little research remains regarding this important topic.

Given the importance of communicating prognosis and the relative absence of guidance for providers, this study sought to describe when and how individuals with CF learn about prognosis and the related emotional impact. We also aimed to identify recommendations for improving communication about prognosis. A qualitative approach was used due to the benefits of this design when exploring new areas, with the goal of highlighting the experiences, feelings, and insight of participants.

\section{Materials and Methods}

Semi-structured interview scripts for each of the three participant groups, including young adults with $\mathrm{CF}$, parents of young adults with $\mathrm{CF}$, and multidisciplinary $\mathrm{CF}$ health care providers, were developed by the research team. Interview questions explored (1) when and how individuals with CF learned about prognosis, (2) the impact of learning about prognosis 
on emotions and on future goal/plans, and (3) recommendations for improving communication about prognosis. Key interview questions are included in Table 2. We defined prognosis as learning about life expectancy and the progressive nature of $C F$. The study protocol and interview script were reviewed and approved by the Institutional Review Boards at the University of North Carolina and the Jacobs School of Medicine, University at Buffalo.

The research team recruited individuals with CF ages 18-25, parents of individuals with CF ages 18-25, and CF health care providers from the pediatric CF care programs at the University of North Carolina and the State University of New York- Buffalo between June 2014 and February 2015. This age range was specifically chosen for patients to ensure that all participants already knew about prognosis and had learned recently enough such that they could recall details of conversations. Hospitalized patients were approached to participate in person, and outpatients by phone prior to a routine $\mathrm{CF}$ clinic appointment. A convenience sample was used for patients based upon presence in the hospital or clinic on recruitment days. All patient interviews were conducted in-person by one of two members of the research team who were trained in qualitative interviewing techniques [JF, CR]. Patients were asked permission for a parent to be approached for participation in the study. Providers, including physicians, nurses, and social workers, were randomly selected and recruited by email. A random number generator was used and paired with a list of providers to ensure random selection as well as sampling across disciplines. Interviews were either conducted in-person or on the phone by one member of the UNC team [JF]. Parent and provider demographics were collected during the interview. Patient disease-specific information was extracted from medical records. Informed consent was obtained from all participants.

Interviews were recorded, transcribed, and de-identified. Summary statistics were used to describe demographic characteristics of study participants and for analysis of responses to closed ended questions. Responses to questions were independently coded from transcripts by two members of the research team [JF, MP]. Qualitative content analysis was used in review of questions about feelings, attitudes, outlook, and goals ${ }^{16}$. The team coded $20 \%$ of transcripts in duplicate, with $91 \%$ inter-coder reliability. Discrepancies were resolved by group discussion. Interviews were stopped when thematic saturation was reached by consensus of the research team.

\section{Results}

We recruited 28 participants from two CF care centers, including 13 young adult patients with $\mathrm{CF}, 8$ parents of young adults with $\mathrm{CF}$, and $7 \mathrm{CF}$ health care providers. Of the patient participants, $46 \%$ were women and the mean age was 21 years (range 18-25 years). A spectrum of lung disease severity was represented, with mean percent $\mathrm{FEV}_{1} 63 \%$ (range: $28-102 \%)$. Seven of the eight parents interviewed were women. Providers included five physicians, one nurse, and one social worker, with a mean of 16 years of experience in $\mathrm{CF}$ care. Interviews ranged from 15 to 75 minutes in length. Subject characteristics are shown in Table 1. 


\section{Learning about prognosis: When and how}

As previously noted, we defined prognosis as both life expectancy and the progressive nature of $\mathrm{CF}$. Patients reported learning about $\mathrm{CF}$ being a progressive disease between the ages of 7 and 19 years, and reported learning about life expectancy between the ages of 8 and 16 years. Parents recalled similar age ranges, $8-16$ years and $10-16$ years, respectively. Most providers believed patients learned this information at an older age than patients reported, typically as teens.

Nearly one-third of patients reported learning about the progressive nature of CF from their CF health care providers, one-third inferred it from their own health decline, and others were told by their parents or learned about this from online resources. An adult recalled, “...I finally realized it was a disease, thanks to Google [and that] hey, I might die soon". Another stated, "I got too much information... because the Internet doesn't hold back. One quarter did not recall how they learned about prognosis. One patient recalled, "No one's really said, 'CF is progressive. But earlier this year, my PFTs were really down, and they were like, 'Maybe this is your new normal." Another recalled that, "the doctors [were] telling me that if I didn't keep up on doing what I need to do, I wouldn't live as long as I should or could." Parents (38\%) and providers (57\%) often identified a patient's own decline in health as the means of learning that $\mathrm{CF}$ is progressive. Both parents and providers also named peers with $\mathrm{CF}$, online resources, the $\mathrm{CF}$ community, parents, and providers as potential sources of this information.

All respondent groups described physicians, parents, and online resources as the most common sources of information about life expectancy. A majority of patients (54\%) reported learning about life expectancy from their CF physician. Half of parents reported being the ones to share this information with their children, while the other half believed their children learned from online resources. Physicians most commonly reported believing that online resources first inform patients about their anticipated life expectancy (57\%).

\section{Emotional response to learning about prognosis}

Patient participants commonly reported a sense that information was "sugarcoated" by whoever shared it with them, either physicians or parents. They also described sometimes feeling this way in general; for example, one participant noted, "I was essentially wrapped in a bubble. You know my mom and dad both were very protective of me ... I've been kind of sidelined most of my life for major events. And it'll probably be like that-well I know it'll be like that now until the day I pass away."They reported a range of emotions, including sadness, fear, disappointment, and stress when learning about prognosis. Many expressed a desire to protect their parents from the emotional burden associated with this information. One patient who felt unaffected emotionally by learning about prognosis believed disease progression would happen to others with CF but not herself. Parents also recalled feelings of denial, and were often sad and overwhelmed when their child learned about prognosis. Some also felt motivated to persevere and take control of CF to the extent possible. Themes related to feelings, attitudes, goals, and recommendations for improving communication are provided in Table 3. 


\section{Effects on attitudes about CF treatments}

Patients most often reported no impact on attitudes about CF treatments (62\%), and $38 \%$ reported a positive impact; none reported a negative impact (e.g., decreased adherence due to emotional distress). A majority of parents (88\%) reported either no change or a positive change in attitudes. Six of the seven providers felt that learning about prognosis does change a patient's attitudes about their CF treatments, in some cases for the better and in some cases for the worse, depending on the individual patient.

\section{Effects on goals and life plans}

Most patients (77\%) did not feel that learning about prognosis affected their personal goals or life plans; those who did felt the impact was positive. One patient said, "I never really thought about it as something that was gonna shorten my life. I never really let that be something that's gonna limit me from my full capabilities." All but one parent felt that learning about prognosis had no impact or positive impact on their child's goals or life plans. All providers said they feel it is not uncommon for goals to shift after conversations about prognosis.

\section{Recommendations for improving communication about prognosis}

Participants were asked who should be involved in communication about prognosis, when prognosis communication should happen, and how it should happen. Patients' responses varied, but $77 \%$ felt that the CF physician should participate in conversations, and $62 \%$ felt parents should be involved. Parents felt similarly to patients, with $88 \%$ wishing to include the $\mathrm{CF}$ physician, and $63 \%$ wanting to be included themselves. Most providers felt a conversation including patients, parents, and a provider would be most appropriate. Some participants from each group felt that these conversations should include non-physician members of the CF health care team.

The range of opinions about the ideal timing of initial communication about prognosis are shown in Figure 1. Across all groups, participants emphasized that the timing should be individualized according to the needs of the patient. Overall, patients and parents suggest early communication about prognosis; patients and parents most commonly suggested elementary school, while providers felt waiting until high school is most appropriate.

When asked how best to share information about prognosis, nearly all patients said a face-toface, individualized conversation is most appropriate. There was only one participant who felt this information should not be shared in person, and suggested giving patients access to online reading materials instead. However, $25 \%$ of patients specifically said it should not be received online. Parents and providers agreed that information about prognosis should be shared with patients face-to-face, but emphasized that some patients may prefer reading materials, online information, or something else entirely (iPad teaching tool or application), again emphasizing attention to individual needs.

When asked about barriers to talking about prognosis with patients, providers most often cited lack of time. Figure 2 outlines other barriers identified by providers, including providers' reluctance to discuss prognosis, the desire to instill hope, waiting for patients to 
ask about prognosis, seeing parents as gatekeepers to conversations, and lack of training and resources. Most routine patient contact occurs in outpatient clinics where time is often short; multidisciplinary CF care team visits tend to be lengthy and exhausting for patients, and finding additional time for conversations about prognosis can prove challenging. Providers also described their own reluctance to discuss the topic. One provider said, "[Sometimes] we don't want to talk about it. And that happens. We're human. Just because we work with kids with CF doesn't mean we want to talk about it with them. It's as hard for us as it is for them so that becomes a barrier." Providers further expressed sometimes waiting for patients or parents to ask about prognosis, some due to their own reluctance and some feeling that patients should be the gatekeepers to this topic. Many providers stated they lack training and/or resources for communicating about prognosis. One provider said, "Sometimes we don't feel comfortable doing it - talking about end of life and all that stuff. It's one of the hardest parts of the new diagnosis talk. So it's just a pending [future] uncomfortable topic because it can make people anxious or more concerned than they already are with their day to day life."This statement reflects another commonly cited barrier: the desire to instill hope and the fear that discussing prognosis indicates that patients should not feel hopeful about their futures.

\section{Discussion}

Currently, there are no guidelines or recommendations for when and how to share information about prognosis with children with CF. Our participants described a gradual awareness and understanding of their illness similar to previously developed cognitive models ${ }^{17-19}$, suggesting that the timing and approach to this communication must take into account a patient's social, emotional, and cognitive development. We found that patients and parents recommend an individualized timeline. Most patient and parent participants recommended conversations about both progression/course and life expectancy earlier rather than later, certainly before high school.

Figure 3 outlines the developmental progression of understanding disease chronicity and prognosis. At younger ages, illness is often understood as something that distinguishes children with CF from peers. Chronicity is inferred through daily treatments and frequent medical appointments. With time, children begin to understand the irreversibility and permanency of CF. Later, they understand not only the physiological components of the illness, but also disease progression and its impact of treatments on symptoms and outcomes, including life expectancy. Many healthy children do not fully understand concepts such as death and dying until 11 years of age ${ }^{20}$. Thus, discussion of this concept in middle school seems appropriate. It is important to note, though, that some studies have shown earlier understanding of disease and death for children with chronic conditions ${ }^{21,22}$. Instead of relying on patients to infer information about CF as they develop, patients and families recommended face-to-face conversations for the purpose of sharing this information. This can prevent knowledge deficits, misinformation, and allow for control over when and how it is presented and received, i.e., in a supportive environment by a physician and parent.

Most patients expressed wanting their physicians to initiate conversations, and a majority felt parents should be included. However, providers shared concerns including their fears of 
causing emotional distress, preferring to wait for patients or parents to bring up the topic. They also expressed concerns about lack of time and lack of support/resources to facilitate conversations about prognosis. With regard to patients' emotional distress, while many patients did acknowledge associated sadness and fear when they learned about prognosis, they also expressed wanting and needing this information. Maintaining hope and the desire to adhere with therapies despite difficult news about prognosis is a common concern, and exploration of hopes and fears can be challenging for CF health care providers. Providers should be reassured by our findings that patients and parents generally report minimal impact on attitudes about treatments or goals regardless of their initial emotional response to learning about prognosis. Providers should also be encouraged to provide information to their patients, given that the explosion of internet use and access in the past decade, as well as increased use of social media for communication within the CF community, has likely led to more children learning about prognosis online today than in the past.

In addition to providing information that empowers children with $\mathrm{CF}$ to manage their disease in accordance with personal goals, earlier communication about prognosis has the potential to open doors to other sensitive but important and sometimes neglected topics. Existing palliative care literature offers resources to providers in the areas of goals of care, advance care planning, and symptom management, and increased attention to palliative care for chronic conditions has led to initiatives to develop resources specific to CF. Our study will inform development of a prognosis communication guide for $\mathrm{CF}$ health care providers and additional resources for patients and parents. These efforts may help address some of the many barriers to communicating prognosis. As outcomes in CF continue to change, it will be important to continue to examine how best to communicate with individuals with $\mathrm{CF}$ and their caregivers about prognosis and other sensitive issues.

Limitations of our study include a small sample from two CF care programs and potential for selection bias based on interest in or concerns about the topic. Additionally, this interview study relied on recall of events, which can be altered with time, and may not be exact. Recall of information in ranges rather than precise numbers in conjunction with our small sample precluded formal comparisons between or among participant groups. This qualitative study is exploratory in nature; future directions may include a larger survey-based study of this important topic.

In summary, individualized, developmentally appropriate conversations between children with $\mathrm{CF}$, their parents, and providers about prognosis are recommended before children reach high school. Future directions include development of prognosis communication guides for $\mathrm{CF}$ health care providers and educational materials for children and parents. These would help providers and families introduce the difficult topic of prognosis, identify the appropriate timing of information sharing, and offer a framework to personalize information and engage patients in communication about this important aspect of CF care.

\section{Acknowledgments}

Funding: This work was supported by the National Institutes of Health grant \# T35-DK007386 and the University of Buffalo Cystic Fibrosis Research Discretionary Indirect Funds Recoverable. 
We are grateful to patient, parent and provider participants for their time and candid comments about this emotionally charged topic.

\section{Abbreviations \\ CF Cystic fibrosis}

\section{References}

1. Cystic Fibrosis Foundation. Annual Data Report. Bethesda, MD: 2016. Patient Registry 2015.

2. Sawicki GS, Sellers DE, McGuffie K, Robinson W. Adults with cystic fibrosis report important and unmet needs for disease information. J Cyst Fibros. 2007; 6:411-6. [PubMed: 17452026]

3. Frayman KB, Sawyer SM. Sexual and reproductive health in cystic fibrosis: a life-course perspective. The Lancet Respiratory medicine. 2015; 3:70-86. [PubMed: 25529340]

4. Dellon EP, Chen E, Goggin J, Homa K, Marshall BC, Sabadosa KA, Cohen RI. Advance care planning in cystic fibrosis: Current practices, challenges, and opportunities. J Cyst Fibros. 2016; 15:96-101. Epub Sep 8. DOI: 10.1016/j.jcf.2015.08.004 [PubMed: 26362396]

5. Dellon EP, Sawicki GS, Shores MD, Wolfe J, Hanson LC. Physician practices for communicating with patients with cystic fibrosis about the use of noninvasive and invasive mechanical ventilation. Chest. 2012; 141:1010-7. [PubMed: 21998257]

6. Sawyer SM, Tully MA, Colin AA. Reproductive and sexual health in males with cystic fibrosis: a case for health professional education and training. J Adolesc Health. 2001; 28:36-40. [PubMed: 11137904]

7. Kazmerski TM, Borrero S, Tuchman LK, Weiner DJ, Pilewski JM, Orenstein DM, Miller E. Provider and Patient Attitudes Regarding Sexual Health in Young Women With Cystic Fibrosis. Pediatrics. 2016:137. [PubMed: 27543009]

8. Faulkner KW. Talking about death with a dying child. The American journal of nursing. 1997; 97:64, 6, 8-9.

9. Nyborn JA, Olcese M, Nickerson T, Mack JW. "Don't Try to Cover the Sky with Your Hands": Parents' Experiences with Prognosis Communication About Their Children with Advanced Cancer. J Palliat Med. 2016; 19:626-31. [PubMed: 27115314]

10. van der Geest IM, van den Heuvel-Eibrink MM, van Vliet LM, Pluijm SM, Streng IC, Michiels EM, Pieters R, Darlington AS. Talking about Death with Children with Incurable Cancer: Perspectives from Parents. J Pediatr. 2015; 167:1320-6. [PubMed: 26427964]

11. Brand SR, Fasciano K, Mack JW. Communication preferences of pediatric cancer patients: talking about prognosis and their future life. Supportive care in cancer: official journal of the Multinational Association of Supportive Care in Cancer. 2017; 25:769-74. [PubMed: 27747479]

12. Spinetta JJ, Jankovic M, Masera G, Ablin AR, Barr RD, Ben Arush MW, D’Angio GJ, Van Dongen-Melman J, Eden T, Epelman C, et al. Optimal care for the child with cancer: A summary statement from the SIOP Working Committee on Psychosocial Issues in Pediatric Oncology. Pediatr Blood Cancer. 2009; 52:904-7. [PubMed: 19142992]

13. Levetown M. Communicating with children and families: from everyday interactions to skill in conveying distressing information. Pediatrics. 2008; 121:e1441-60. [PubMed: 18450887]

14. Knopf JM, Hornung RW, Slap GB, DeVellis RF, Britto MT. Views of treatment decision making from adolescents with chronic illnesses and their parents: a pilot study. Health Expect. 2008; 11:343-54. [PubMed: 19076663]

15. Hames A, Beesley J, Nelson R. Cystic fibrosis: what do patients know, and what else would they like to know? Respir Med. 1991; 85:389-92. [PubMed: 1759003]

16. Hsieh HF, Shannon SE. Three approaches to qualitative content analysis. Qual Health Res. 2005; 15:1277-88. [PubMed: 16204405]

17. Bibace R, Walsh ME. Development of children's concepts of illness. Pediatrics. 1980; 66:912-7. [PubMed: 7454481]

18. Piaget J. Cognitive development in children: Piaget development and learning. J Res in Sci Teaching. 1964; 2:176-80. 
19. Piaget, J. The Origins of Intelligence in Children. New York, NY: International University Press; 1952.

20. American Academy of Pediatrics. Committee on Psychosocial Aspects of Child and Family Health Pediatrics. The pediatrician and childhood bereavement. 2000; 105:445-7.

21. Bluebond-Langner, M. The Private Worlds of Dying Children. Princeton, NJ: Princeton University Press; 1978.

22. Freyer DR. Care of the dying adolescent: special considerations. Pediatrics. 2004; 113:381-8. [PubMed: 14754953] 


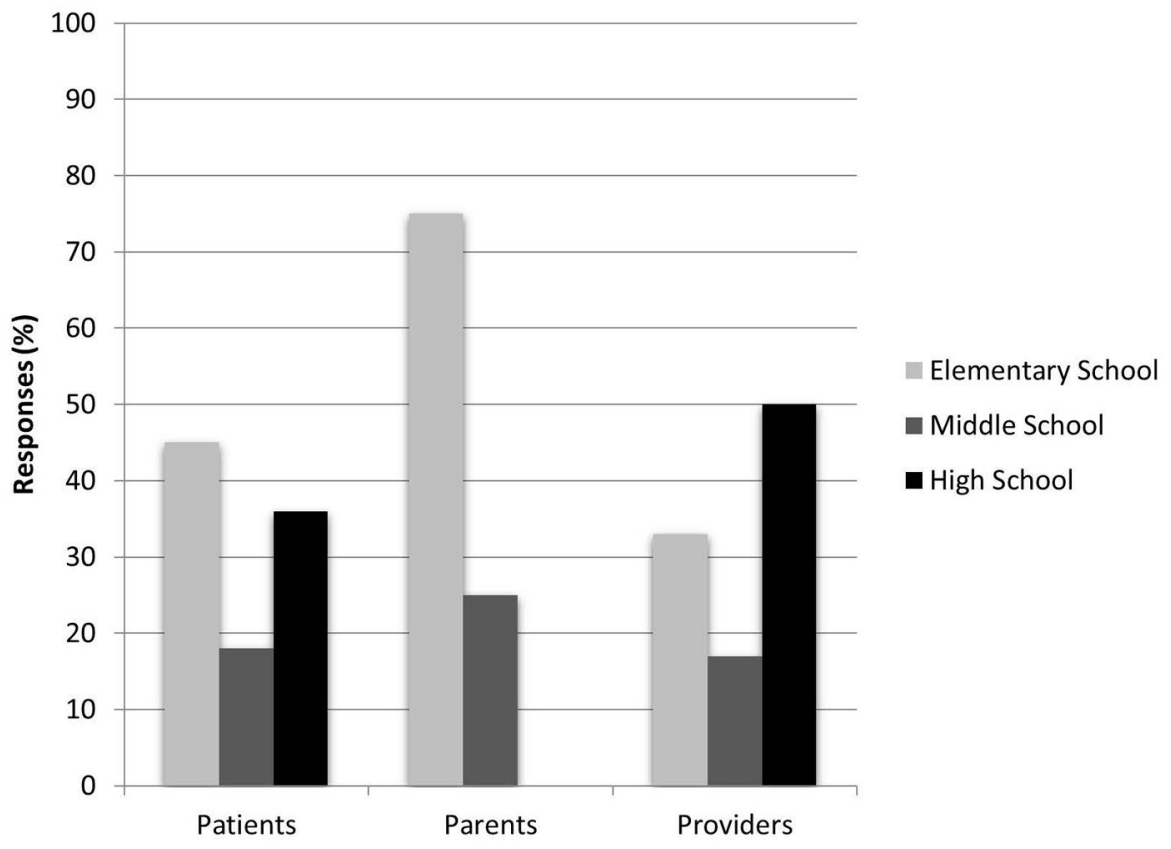

Figure 1.

Participant recommendations for when to discuss prognosis 


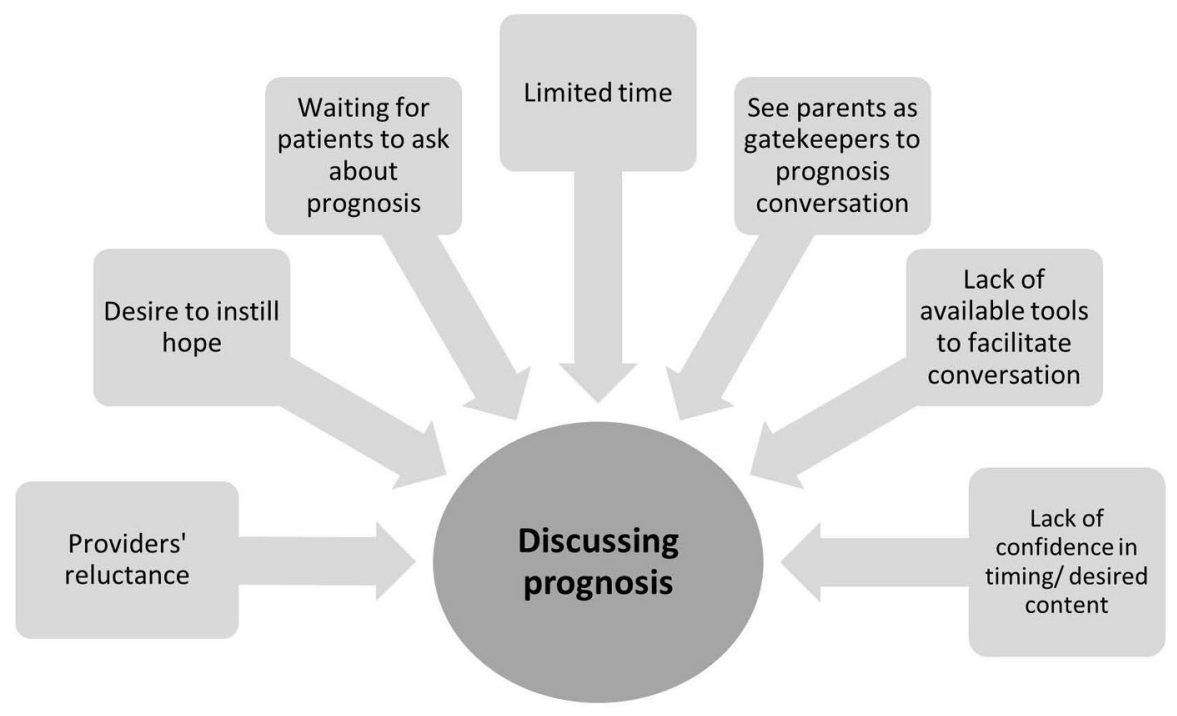

Figure 2.

Provider-reported barriers to communicating about prognosis 


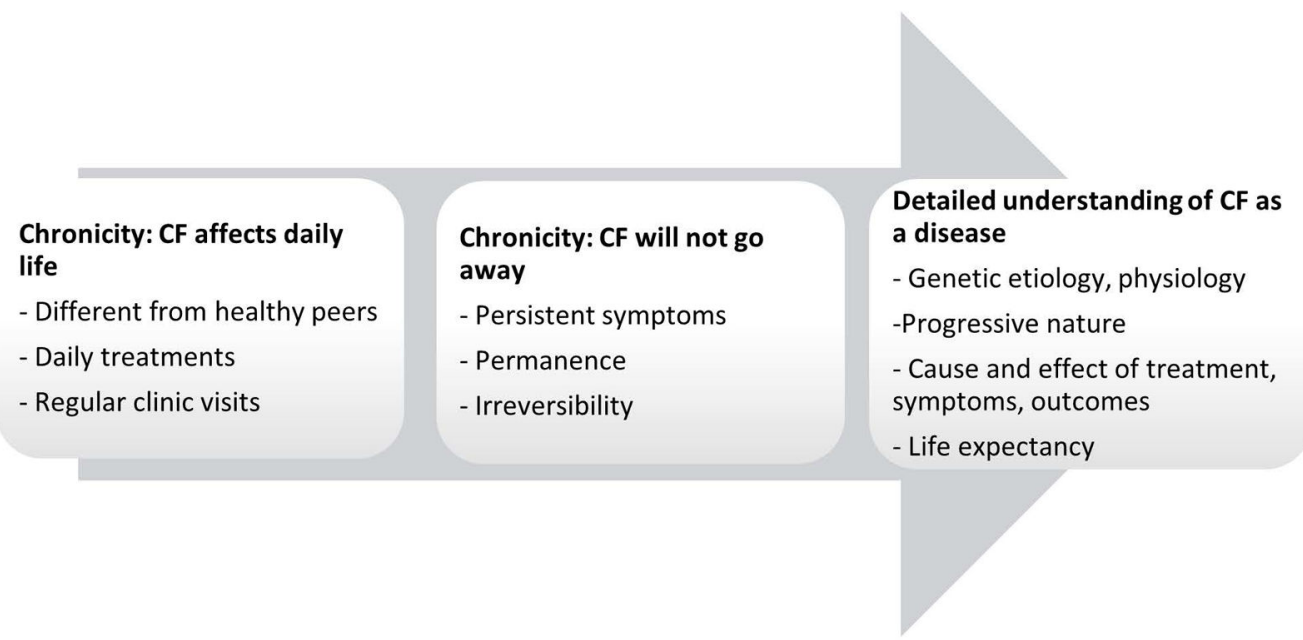

Figure 3.

Patient developmental progression of disease understanding 


\section{Table 1}

\begin{tabular}{|c|c|c|}
\hline \multirow{6}{*}{ 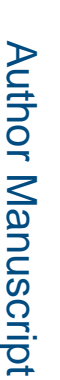 } & \multicolumn{2}{|l|}{ Participant demographics } \\
\hline & Patients with $\mathrm{CF}$ (N=13) & $\mathrm{N}(\%)$ or mean (range) \\
\hline & Female gender & $6(54)$ \\
\hline & Mean age in years (range) & $21(18-25)$ \\
\hline & FEV1 percent predicted & $63(28-102)$ \\
\hline & BMI $\left(\mathrm{kg} / \mathrm{m}^{2}\right)$ & $19.84(14.5-25.1)$ \\
\hline & \multicolumn{2}{|l|}{ Parents $(\mathbf{N}=8)$} \\
\hline & Female gender & $7(88 \%)$ \\
\hline & Mean age in years (range) & $55(47-72)$ \\
\hline & Mean age of child in years (range) & $22(18-24)$ \\
\hline & Female gender of child & $7(88 \%)$ \\
\hline & \multicolumn{2}{|l|}{ Healthcare Providers (N=7) } \\
\hline & \multicolumn{2}{|l|}{ Profession } \\
\hline & Physician & $5(71 \%)$ \\
\hline & Nurse & $1(14 \%)$ \\
\hline & Social Worker & $1(14 \%)$ \\
\hline & Mean experience caring for patients with $\mathrm{CF}$ in years (range) & $17(2-28)$ \\
\hline & \multicolumn{2}{|l|}{ Patient population served } \\
\hline & Pediatrics Only & $4(57 \%)$ \\
\hline & Pediatrics \& Adult & $3(43 \%)$ \\
\hline
\end{tabular}




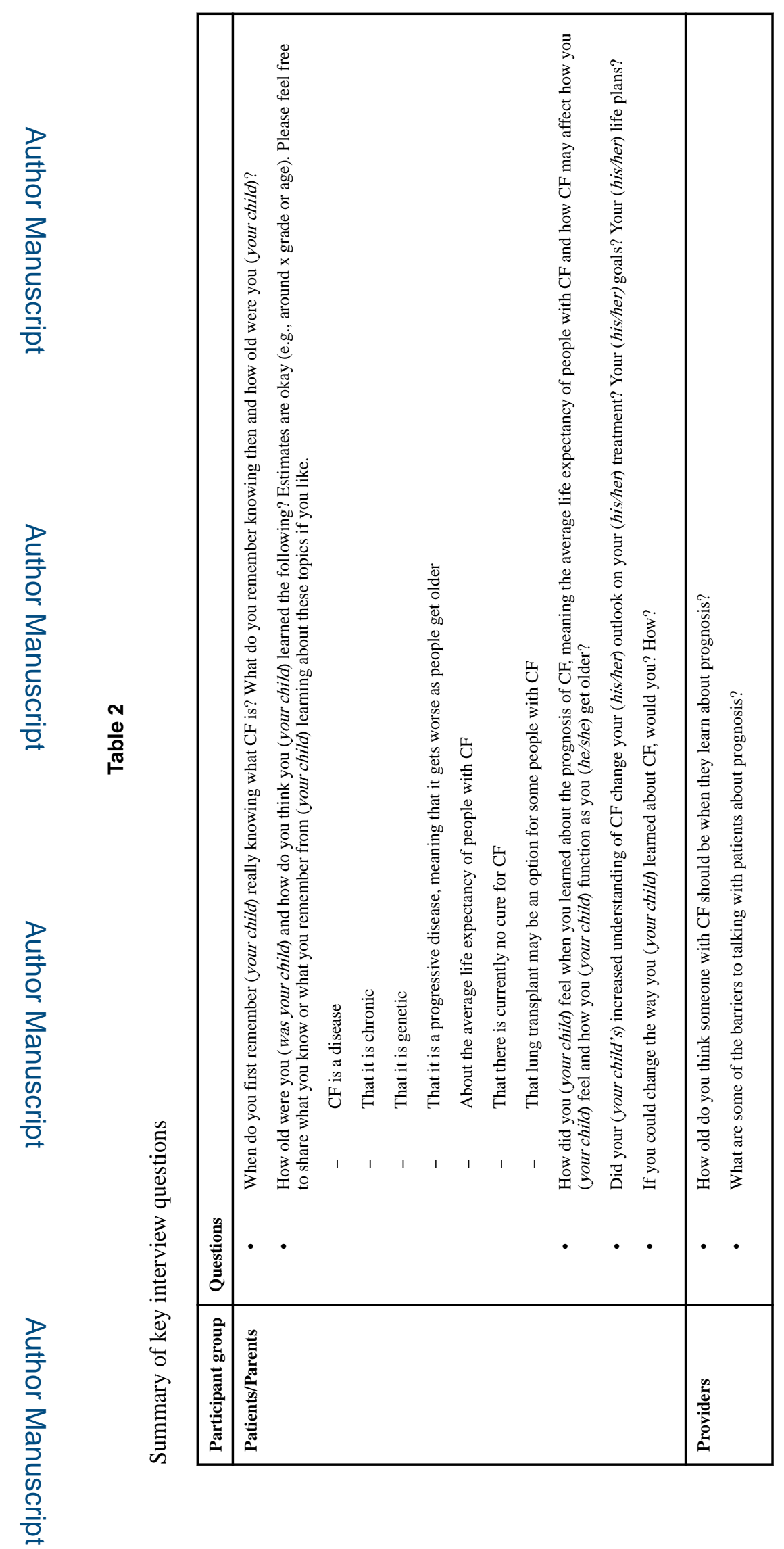

Pediatr Pulmonol. Author manuscript; available in PMC 2019 May 01. 


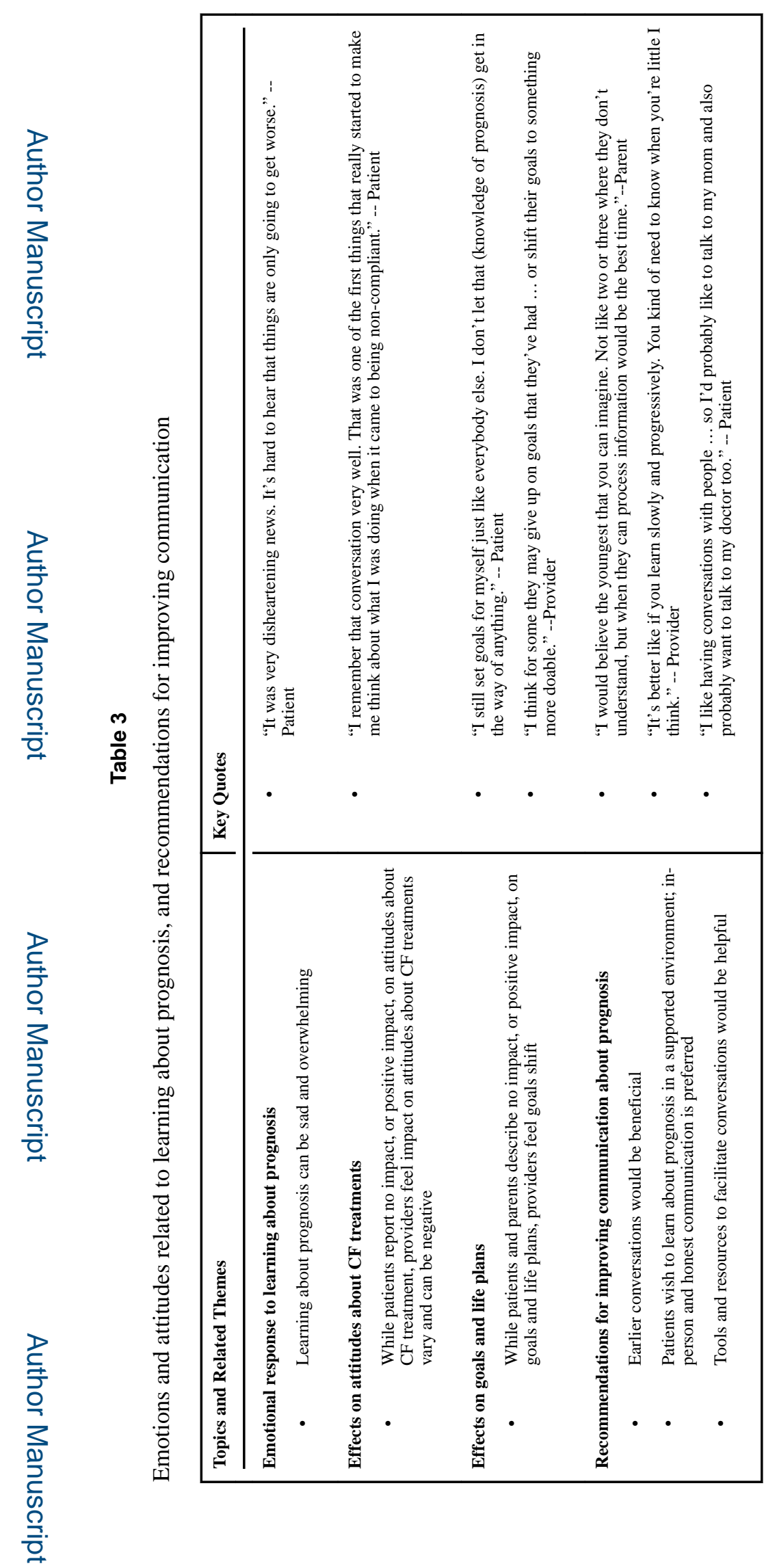

Pediatr Pulmonol. Author manuscript; available in PMC 2019 May 01. 